\title{
POSTMORTEM GHANGES IN THE RAT KIDNEY I. HISTOPATHOLOGICAL, ELECTRON MICROSCOPICAL, AND ENZYME HISTOCHEMICAL STUDIES OF POSTMORTEM CHANGES AT ROOM TEMPERATURE
}

\author{
Takayasu ITO, Takao ANDO, Hiroshi MAYAHARA, Hiroaki MiYAjima \\ and KAZUO OGAWA* \\ Drug Safety Research Laboratories, Takeda Chemical Industries, Ltd., Himuro-cho, \\ Takatsuki, Osaka 569 and Department of Anatomy*, Faculty of Medicine, \\ Kyoto University, Yoshida, Sakyo, Kyoto 606
}

Received for publication February 25, 1991

\begin{abstract}
To get a better understanding of the factors that are related to the rapidity of the postmortem changes, we studied the postmortem changes in various parts of the nephron in the rat kidney at room temperature histopathologically, electron microscopically, and enzyme histo- and cytochemically. We found that the rapidity of the postmortem changes in the tubular epithelia of the rat kidney, at room temperature, is related to the intensity of cellular K-NPPase activity, that is the partial phosphatase activity of $\mathrm{Na}, \mathrm{K}$ ATPase. The postmortem changes, characterized by cytoplasmic vacuolization and karyopyknosis, in the epithelial cells in the distal tubule and the thick ascending limb of the loop of Henle (TAL) with intense KNPPase activity began earlier and progressed faster than those in the epithelia of the proximal tubules, macula densa and other parts of the nephron with low K-NPPase activity. These postmortem changes were delayed by flushing the kidney with PBS containing ouabain, ATP, verapamil, or EDTA. It is probable that the cells with intense ATPase activity tend to consume intracellular ATP faster than the cells with low ATPase activity after death, and the resulting lack of intracellular ATP and calcium ion influx cause various postmortem changes. On the other hand, the postmortem changes in the proximal tubules, with a large number of lysosomes, are slower and milder than those in the distal tubules and TAL at room temperature. Enzyme cytochemistry revealed hardly any signs of leakage of acid phosphatase, one of the lysosomal hydrolytic enzymes, up to at least $10 \mathrm{hr}$ after death, during which time, the postmortem changes in the proximal tubules are slight and those in the distal tubules and TAL are severe.

These results suggest that the rapidity of the postmortem changes in the rat kidney at room temperature depends mainly on the intensity of cellular $\mathrm{Na}, \mathrm{K}$-ATPase activity and that lysosomes do not participate in the cellular postmortem changes to a great extent until at least $10 \mathrm{hr}$ after death.
\end{abstract}

In the histopathological examination in toxicity studies using laboratory animals, it is important to differentiate postmortem changes from toxic changes caused by the test compound when animals are found dead during the dosing period. Thus, an attempt was made in our laboratory to obtain data on the postmortem changes in various organs and tissues. We studied histopathologically the postmortem changes in various organs and tissues at room temperature up to $20 \mathrm{hr}$ after death in rats sacrificed by ether anesthesia (15). During the course of that study, we found that the rapidity of the postmortem changes in the rat kidney varies with the part of the nephron: at room temperature, epithelial cells in the distal tubules and the thick ascending limb of the loop of Henle show faster postmortem changes, which were characterized by cytoplasmic vacuolization and karyopyknosis, than do other parts of the nephron $(16,23)$.

In the present study, postmortem changes in the various parts of the nephron in the rat kidneys were studied histopathologically and electron microscopically. Potassium-dependent $p$-nitrophenyl phosphatase (K-NPPase), the partial phosphatase activity of $\mathrm{Na}$, $\mathrm{K}$-ATPase $(1,11,17)$, whose activity is intense in the 
distal tubules and thick ascending limb of the loop of Henle (24), and acid phosphatase (ACPase), a marker enzyme of the lysosomes which contain various kinds of peptidases or amidases $(2-5,7,8,28)$ and is generally thought to be related to autolysis of cells (9), were examined enzyme histo- and cytochemically to get a better understanding of the factors that are related to the rapidity of the postmortem changes in the different types of cells.

Since the results of the above examinations lead us to an assumption that the rapidity of the postmortem changes depends on the rapidity of the consumption of intracellular ATP, we studied the effect of Na, K-ATPase inhibition or ATP supplementation on the rapidity of the postmortem changes at room temperature in the rat kidneys by flushing them with phosphate-buffered saline (PBS) containing ouabain or ATP. On the other hand, it has been reported that an influx of extracellular calcium ions into the cells occurs following a decrease in intracellular ATP, and the increase in the concentration of intracellular calcium ions causes damage to the membrane and cytoskeleton $(6,20,25-27,29,31)$. Therefore, we studied the relationship between the intracellular calcium concentration and the rapidity of the postmortem changes in the rat kidney at room temperature by flushing the kidney with PBS containing verapamil, a calcium channel blocker (10), or EDTA, a calcium chelator.

\section{MATERIALS AND METHODS}

Eight- to ten-week-old male Wistar rats were used. The animals were sacrificed by ether anesthesia and were placed at room temperature $\left(22 \pm 3^{\circ} \mathrm{C}\right)$ in metal cages. The kidneys were removed $0,1,5,10$, 15 , and $20 \mathrm{hr}$ after death.

A. Histopathology

Pieces of the kidney were fixed in 10\% neutral buffered formalin, embedded in paraffin, sectioned into pieces about $4 \mu \mathrm{m}$ thick, and stained with hematoxylin and eosin (H.E).

B. Enzyme histo- and cytochemistry of potassiumdependent $p$-nitrophenyl phosphatase (K-NPPase) activity

The kidneys were cut transversely into slices less than $1 \mathrm{~mm}$ thick and fixed in a mixture of $2 \%$ paraformaldehyde and $0.5 \%$ glutaraldehyde buffered with $50 \mathrm{mM}$ piperazine- $\mathrm{N}, \mathrm{N}^{\prime}$-bis (2-ethanesulfonic acid) (PIPES), $\mathrm{pH} 7.4$, for $2 \mathrm{hr}$ at $0^{\circ} \mathrm{C}$.

For histochemistry, each fixed slice was cut into $10 \mu \mathrm{m}$-thick frozen sections with a cryostat (AO Richert Scientific Instruments, New York) and in- cubated in the medium for the K-NPPase assay prepared by the method of Mayahara et al. (22) for 10 to $15 \mathrm{~min}$ at room temperature. The sections were then rinsed in distilled water, treated with $1 \%$ yellow ammonium sulfide for $2 \mathrm{~min}$, rinsed in distilled water, and mounted on a slide glass with glycerine-jelly.

For cytochemistry, $40 \mu \mathrm{m}$-thick non-frozen sections were cut with a Microslicer (DTK-1000, Dosaka EM Co., Ltd., Kyoto) and incubated in the aforementioned medium for K-NPPase. Sections were then postfixed with $1 \%$ osmium tetroxide buffered with $50 \mathrm{mM}$ PIPES containing $0.25 \mathrm{M}$ sucrose for $30 \mathrm{~min}$ at $0^{\circ} \mathrm{C}$, dehydrated through a graded ethanol series, and embedded in Spurr's resin (30). These embedded sections were cut with an Ultrotome (NOVA, LKB-Produkter AB, Bromma), post-stained with uranyl acetate, and examined using an electron microscope (JEM-1200EX, JEOL, Tokyo).

The final concentration of each compound in the incubation medium was as follows (22):

Glycine-KOH buffer, $\mathrm{pH} 9.0$

$$
250 \mathrm{mM}\left(\mathrm{K}^{+}: 25 \mathrm{mM}\right)
$$

Lead citrate (dissolved in $50 \mathrm{mM} \mathrm{KOH}$ )

$$
\text { Dimethylsulfoxide (DMSO) }
$$

$$
4.0 \mathrm{mM}\left(\mathrm{K}^{+}: 20 \mathrm{mM}\right)
$$

$$
\begin{aligned}
& 25 \%(\mathrm{v} / \mathrm{v}) \\
& p \text {-nitrophenyl phosphate (magnesium salt) } \\
& \text { Levamisole } \quad 2.5 \mathrm{mM} \\
& 10 \mathrm{mM}\left(\mathrm{Mg}^{2+}: 10 \mathrm{mM}\right)
\end{aligned}
$$

C. Electron microscopy (morphology)

Small pieces of the kidneys were fixed in a mixture of $2 \%$ paraformaldehyde and $2 \%$ glutaraldehyde buffered with $50 \mathrm{mM}$ PIPES, postfixed in $1 \%$ osmium tetroxide buffered with $50 \mathrm{mM}$ PIPES containing $0.25 \mathrm{M}$ sucrose, embedded in Spurr's resin, cut with an Ultrotome, stained with uranyl acetate and lead citrate, and examined under an electron microscope.

D. Enzyme histo- and cytochemistry of acid phosphatase (ACPase) activity

The kidneys were cut transversely into slices less than $1 \mathrm{~mm}$ thick and fixed in a mixture of $2 \%$ paraformaldehyde and $2 \%$ glutaraldehyde buffered with $50 \mathrm{mM}$ PIPES, $\mathrm{pH} 7.4$, for $2 \mathrm{hr}$ at $0^{\circ} \mathrm{C}$. Frozen or non-frozen sections were made by the same method as that used for enzyme histo- and cytochemistry of KNPPase. The sections were incubated in the medium for the ACPase assay prepared by the method of Gomori (13) for 10 to $15 \mathrm{~min}$ at $37^{\circ} \mathrm{C}$, and specimens were processed and examined in the same way as for K-NPPase.

The final concentration of each compound in the incubation medium was as follows (13):

$0.05 \mathrm{M}$ Acetate buffer, $\mathrm{pH} 5.0$ 
Sucrose

Lead nitrate

Sodium $\beta$-glycerophosphate

$230 \mathrm{mM}$

$3.0 \mathrm{mM}$

$10 \mathrm{mM}$

E. Flushing with PBS containing ouabain, ATP, verapamil, and EDTA

An incision was made in the abdomen of rats under ether anesthesia; the abdominal aorta was clamped at the cranial side of the division point to the left renal artery, and an incision was made in the left renal vein. The left kidney was then flushed with $5 \mathrm{ml}$ of a flush solution from the lower abdominal aorta using an injection needle (21G) and a syringe. Sufficient flushing was confirmed by pale discoloration of the left kidney. After flushing, the left renal artery and vein were cut off at the renal hilus to prevent the influx of blood into the left kidney. The animals were then exsanguinated from the abdominal aorta. The blood in the abdominal cavity was removed, the abdominal incision was closed with clips, and the animals were left at room temperature $\left(22 \pm 3^{\circ} \mathrm{C}\right)$ for $5 \mathrm{hr}$. The flush solutions used were as follows:

a. vehicle (Dulbecco's phosphate buffered saline, PBS)

b. $10 \mathrm{mM}$ ouabain (ouabain octahydrate) in PBS

c. $10 \mathrm{mM}$ ATP (adenosine triphosphate, dipotassium salt) in PBS

d. $1 \mathrm{mM}$ verapamil (verapamil hydrochloride) in PBS

e. $10 \mathrm{mM}$ ouabain $+1 \mathrm{mM}$ verapamil in PBS

f. $10 \mathrm{mM}$ ouabain +EDTA (ethylenediaminetetraacetic acid, tetrasodium salt) in PBS

g. $10 \mathrm{mM} \mathrm{ATP}+1 \mathrm{mM}$ verapamil in PBS

PBS was purchased from Nissui Seiyaku Co., Ltd. (Japan), ouabain from Aldrich Chemical Company, Inc. (U.S.A.), verapamil and EDTA from Wako Pure Chemical Industries, Co., Ltd. (Japan), and ATP from Sigma Chemical Company (U.S.A.).

Five hr after death, the left kidney was removed from each animal, and examined histopathologically and electron microscopically.

\section{RESULTS}

A. Chronological course of the postmortem changes in each portion of the nephron

Postmortem changes in each portion of the nephron in the rat kidney examined histopathologically are summaried in Table 1 .

The structure of the normal rat kidney fixed immediately after death is shown in Fig. 1a (cortex) and Fig. 1b (inner stripe of the outer medulla). One hr after death no appreciable changes were observed in the cortex (Fig. 2a), inner stripe of the outer medulla (Fig. 2b) or other portions, as shown in the table.

Five hr after death, karyopyknosis and cytoplasmic vacuolization were seen in the epithelium of the distal tubules, however, only slight karyopyknosis was seen in the epithelium of the proximal tubules (Fig. 3a). No appreciable changes were seen in the glomeruli or collecting tubules. In the medulla, karyopyknosis and cytoplasmic vacuolization, as observed in the distal tubules, were seen in the epithelium of the thick ascending limb of the loop of Henle (TAL) (Fig. 3b).

Ten hr after death, the severity of the changes in the distal tubules and TAL had progressed. The changes in the other portions were the same as those seen $5 \mathrm{hr}$ after death.

Fifteen hr after death, the changes in the distal tubules and TAL were severer. Karyopyknosis and cytoplasmic vacuolization were seen in the cells of the convoluted proximal tubules, however, no vacuoliza-

TABLE 1. Severity of postmortem changes at room temperature and intensity of $K$-NPPase activity in rat kidney

\begin{tabular}{|c|c|c|c|c|c|c|c|}
\hline & \multicolumn{6}{|c|}{ Time after death (hr) } & \multirow{2}{*}{$\begin{array}{l}\text { K-NPPase activity } \\
\text { in normal rat }\end{array}$} \\
\hline & 0 & 1 & 5 & 10 & 15 & 20 & \\
\hline Glomerulus (Podocyte) & - & - & - & - & - & \pm & - \\
\hline Proximal (Convoluted) & - & - & \pm & \pm & + & + & + \\
\hline Proximal (Straight) & - & - & \pm & \pm & \pm & \pm & \pm \\
\hline Henle's loop (Thin) & - & - & - & - & - & - & - \\
\hline Henle's loop (Thick ascending limb) & - & - & + & H & $H$ & $H$ & $H$ \\
\hline Distal (Except for macula densa) & - & - & + & H & H & H & H \\
\hline Collecting (Cortex) & - & - & - & - & + & + & + \\
\hline Collecting (Medulla) & - & - & - & - & - & \pm & - \\
\hline
\end{tabular}

Grades of postmortem changes were determined based on severity and frequency of karyopyknosis and cytoplasmic vacuolization of the epithelial cells examined by light microscopy and are expressed as follows: - , none, \pm , very slight; + , slight; $H$, moderate; $H$, severe. 

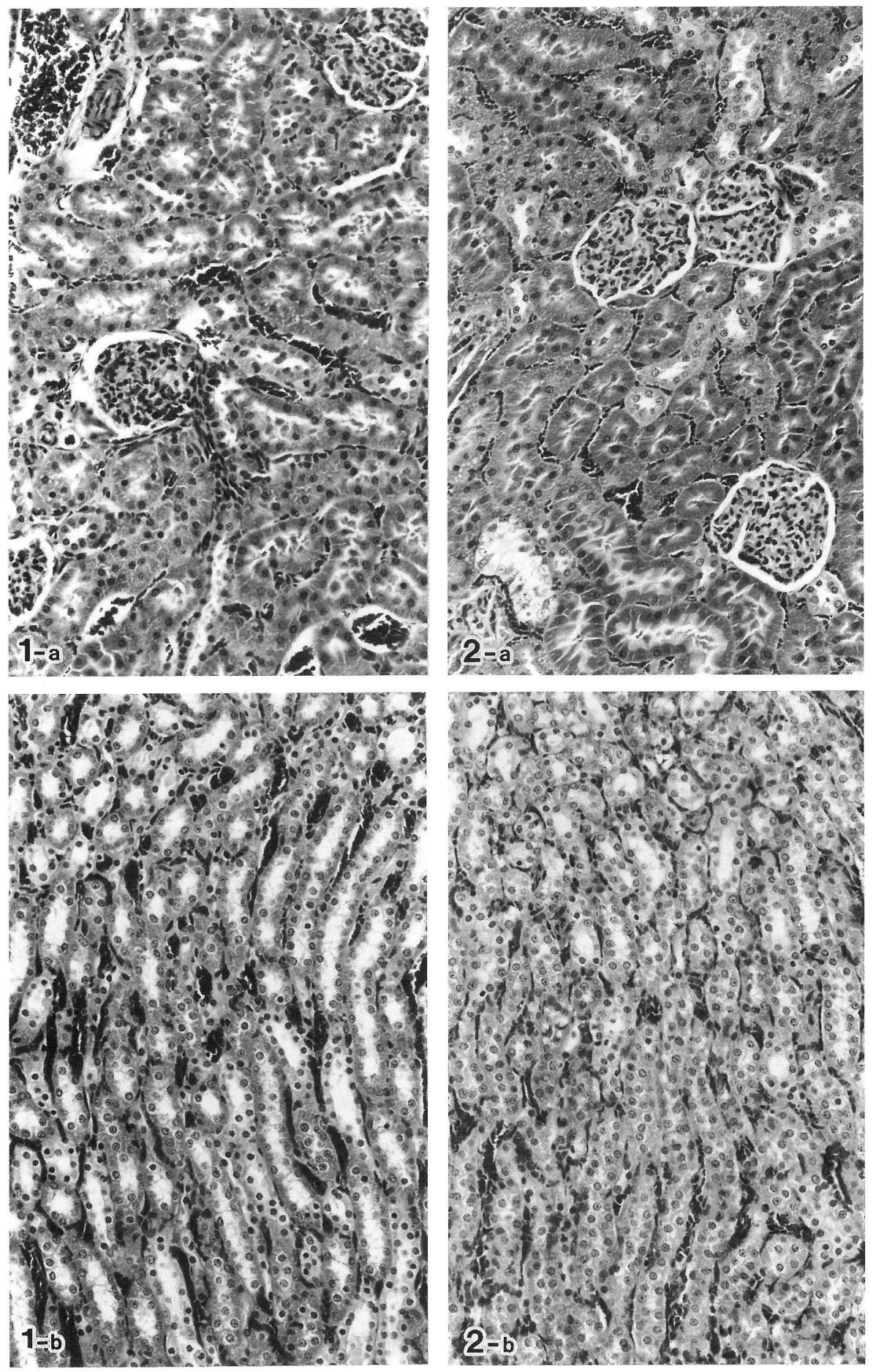

Figs. 1a, b. Cortex (a) and outer medulla (b) of normal rat kidney fixed immediately after death. HE stain. $\times 175$

Figs. 2a, b. Cortex (a) and outer medula (b) of normal rat kidney $1 \mathrm{hr}$ after death. No obvious changes are observed. HE stain. $\times 175$ 

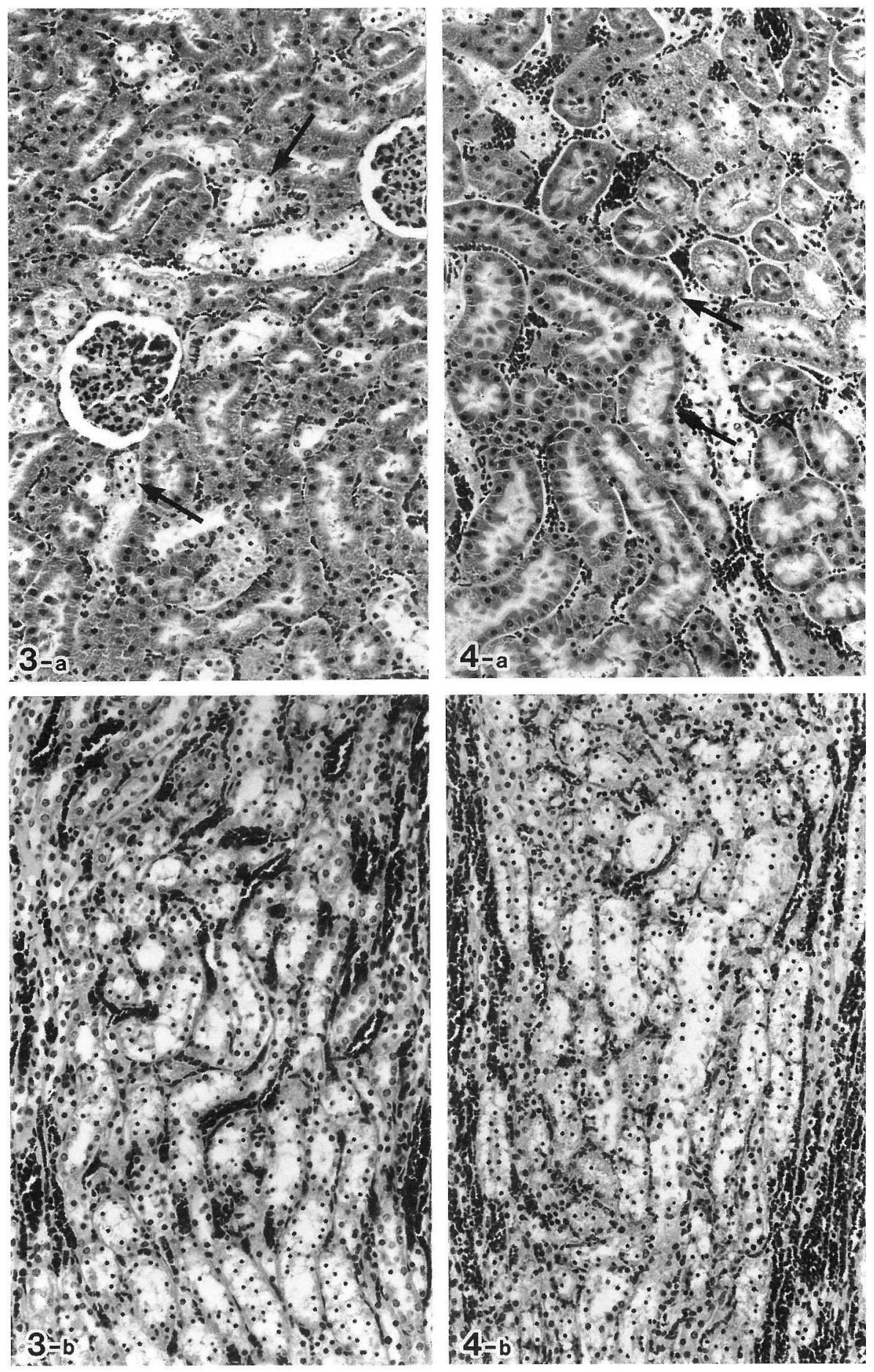

Figs. 3a, b. The kidney $5 \mathrm{hr}$ after death. a. Cortex. Karyopyknosis and cytoplasmic vacuolization are seen in the epithelia of the distal tubules (arrows), however, only slight karyopyknosis is seen in the epithelia of the proximal tubules. b. Outer medulla Karyopyknosis and cytoplasmic vacuolization are seen in the epithelia of the thick ascending limb of the loop of Henle. HE stain. $\times 175$

Figs. 4a, b. The rat kidney $15 \mathrm{hr}$ after death. a. Cortex. Karyopyknosis and cytoplasmic vacuolization are seen in the epithelia of the distal tubules. However, these changes are milder in the epithelia of the proximal convoluted tubules. Almost no cytoplasmic vacuolization is seen in the epithelia of the proximal straight tubules (arrows). b. Outer medulla. Severe karyopyknosis and cytoplasmic vacuolization are seen in the epithelia of the thick ascending limb of the loop of Henle. HE stain. $\times 175$ 
tion was seen in the cells of the straight proximal tubules (Fig. 4a). Severe kayopyknosis and cytoplasmic vacuolization were seen in the TAL (Fig. 4b), and the extent was the same as that seen $10 \mathrm{hr}$ after death. Mild vacuolization was seen in the glomerular epithelia and collecting tubules.

Twenty hr after death, the findings were the same as those observed $15 \mathrm{hr}$ after death in the cortex and the inner stripe of the outes medulla.

B. Enzyme histochemistry of K-NPPase activity

In the normal rat kidney, the histochemical intensity of K-NPPase activity is strongest in the distal tubules (Fig. 5a), and second strongest in the TAL (Fig. 5b). In the other portions including the prox-
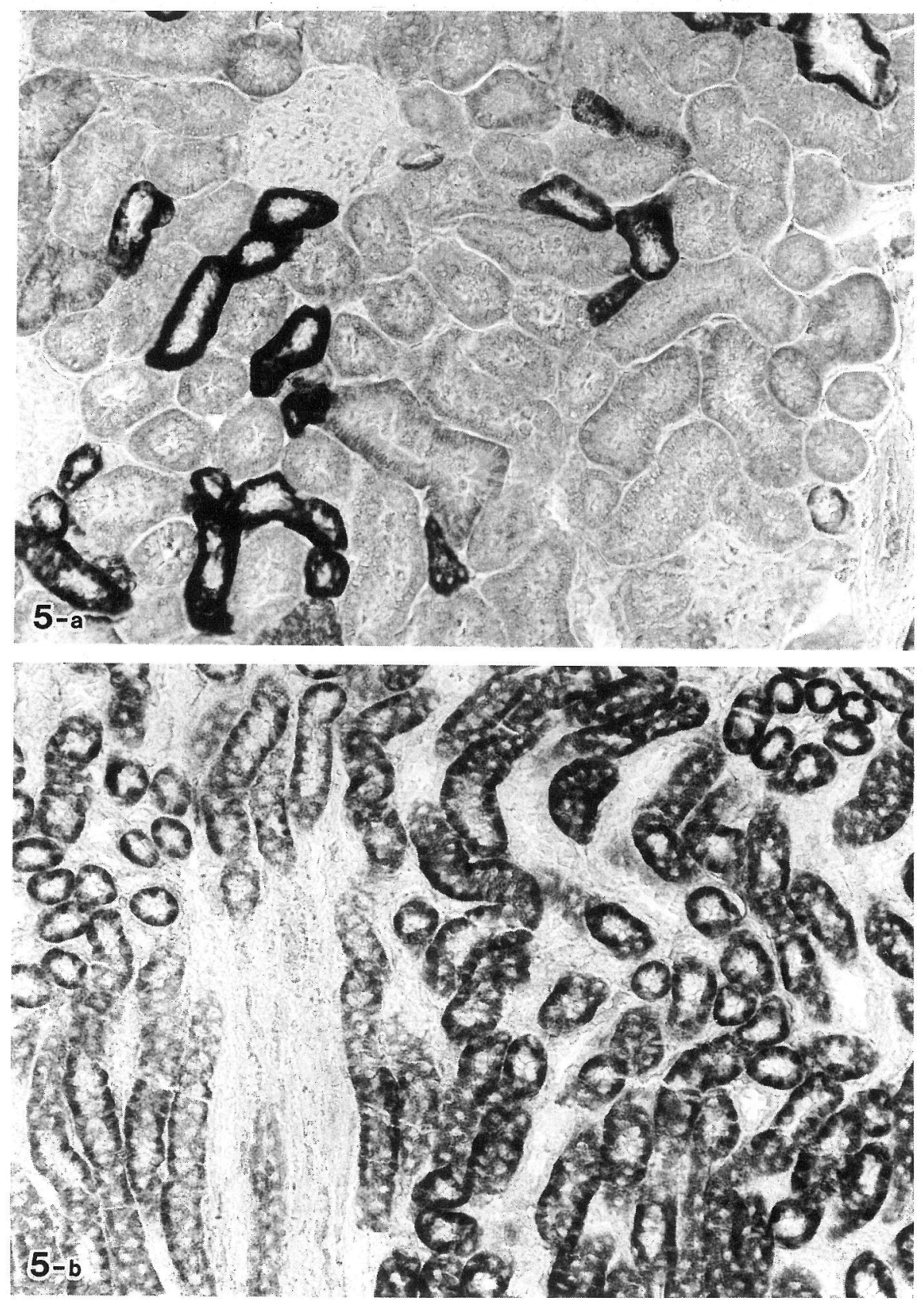

Figs. 5a, b. K-NPPase activity in the control rat. a. Cortex. Intense K-NPPase activity is observed in the epithelia of the distal tubules. b. Outer medulla. Intense K-NPPase activity is observed in the epithelia of the thick ascending limb of the loop of Henle. $\times 175$ 
imal tubules, K-NPPase activity was very weak or not detected. The intensity of K-NPPase activity in the each portion of the nephron is shown on the right side of Table 1.

Comparing the intensity of K-NPPase activity and the severity of the postmortem changes in each portion of the nephron, the distal tubules and TAL with strong K-NPPase activity showed the most severe postmortem changes, karyopyknosis and cytoplasmic vacuolization, and these changes progressed rapidly.
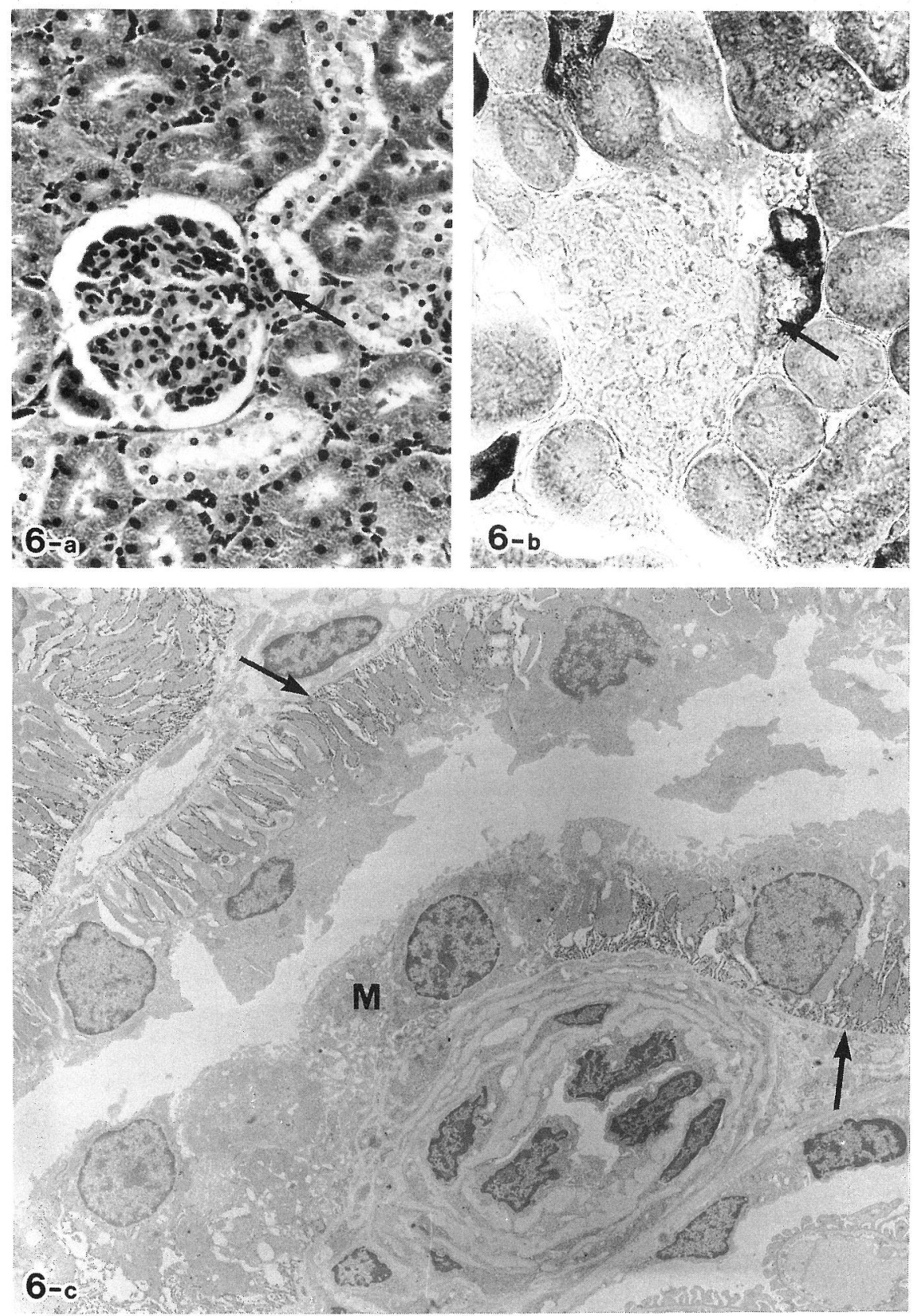

FIGs. 6a-c. The macula densa of the rat kidney. a. $5 \mathrm{hr}$ after death. The epithelia of the distal tubules show karyopyknosis and cytoplasmic vacuolization; however, the epithelia of the macula densa (arrow) show almost no changes. HE stain. $\times 231$ b. KNPPase activity in the control rat. The epithelia of the distal tubules show strong enzyme activity; however, almost no enzyme activity is seen in the epithelia of the macula densa (arrow). $\times 231$. c. Electron micrograph of K-NPPase activity in the control rat. Enzyme activity is shown on the membrane of the basal infoldings of the epithelia in the distal tubule (arrows) but not in those of the macula densa $(\mathrm{M}) . \quad \times 2,600$ 
However, in the epithelia with weak K-NPPase activity the postmortem changes were mild and the occurence delayed.

C. Postmortem changes in the macula densa

The macula densa is a group of epithelial cells in the distal tubules adjacent to the afferent arterioles. The regular epithelial cells in the distal tubules showed postmortem changes, karyopyknosis and cytoplasmic vacuolization, beginning $5 \mathrm{hr}$ after death, as mentioned above. However, the postmortem changes in the cells of the macula densa were milder than those seen in the distal tubules adjacent to the macula densa (Fig. 6a, arrow). Histochemically, K-NPPase activity in the macula densa was far weaker than that observed in
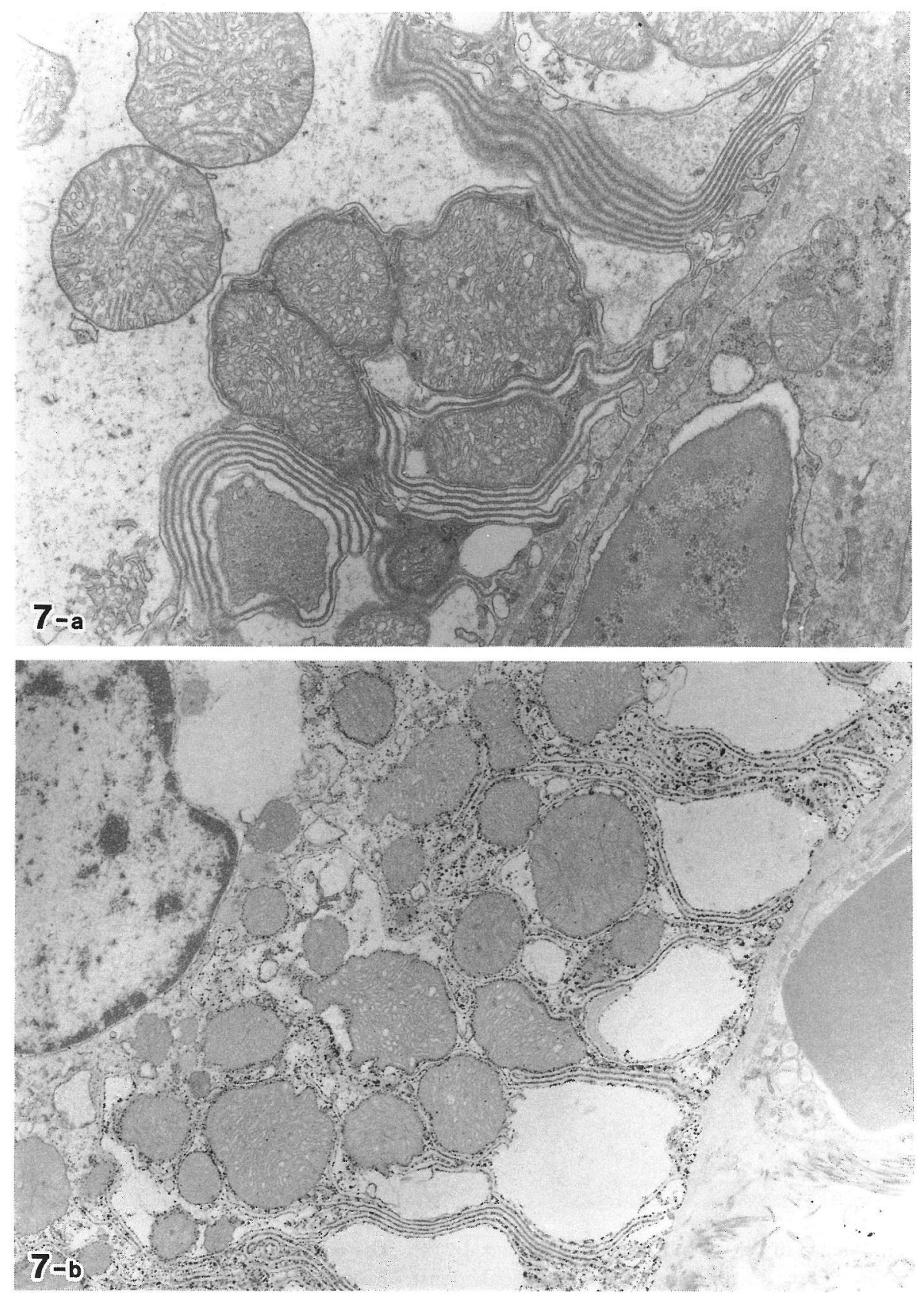

Figs. 7a, b. Electron micrographs of the distal tubule $5 \mathrm{hr}$ after death. a. The micrograph shows swollen mitochondria, and disordered and layered basal infoldings. $\times 15,000$ b. K-NPPase activity is still present on the membrane of the altered basal infoldings. $\times 7,500$ 
the distal tubules (Fig. 6b, arrow). Cytochemically, the reaction products indicating K-NPPase activity were observed along the cytoplasmic membrane of the basal infoldings of the cells in the distal tubules, but were not observed in the epithelia of the macula densa (Fig. 6c, M).
D. Electron microscopy of the postmortem changes in the distal tubules

Electron microscopically, coagulated nuclear chromatin, cytoplasmic vacuoles which were not dilated endoplasmic reticulum, swollen mitochondria and laminated infoldings were observed in the
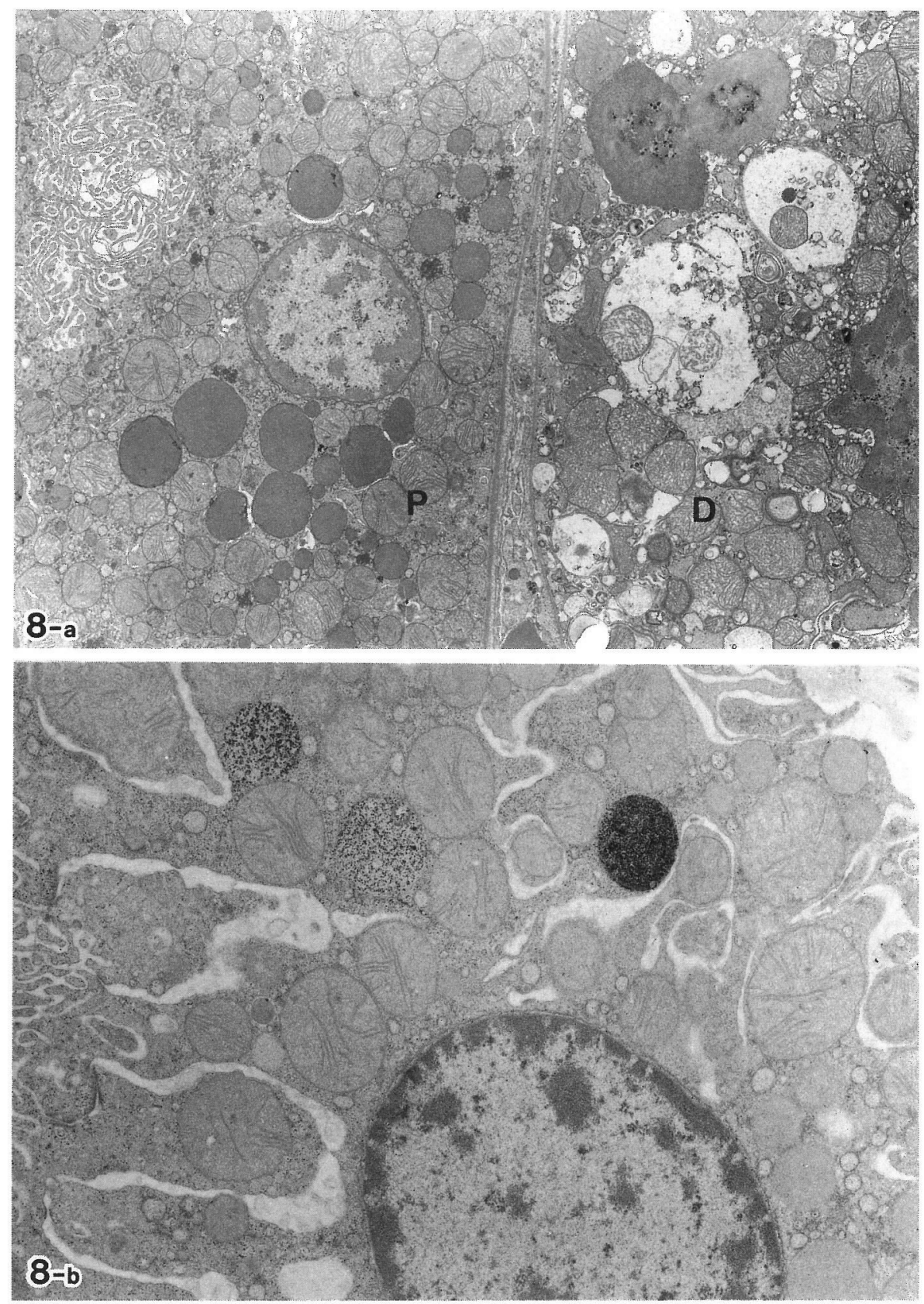

Figs. 8a, b. Electron micrographs of the renal tubule $5 \mathrm{hr}$ after death. a. A distal tubule cell (D) shows coagulated nuclear chromatin, cytoplasmic vacuoles, swollen mitochondria, and disordered basal infoldings. However, the proximal tubule cell (P) shows only mild swelling of mitochondria, and disordered microvilli. $\times 4,500$ b. ACPase activity in a proximal tubule cell. Activity is localized in lysosomes which show no appreciable leakage of ACPase. $\quad \times 10,100$ 
epithelial cells of the distal tubules $5 \mathrm{hr}$ after death (Fig. 7a). On the cytoplasmic membrane of the laminar structures, the reaction products indicating K-NPPase activity were observed (Fig. 7b).

E. Electron microscopy of the postmortem changes in the proximal tubules

Mildly coagulated nuclear chromatin, mildly swollen mitochondria, and disordered microvilli were seen in the proximal tubules $5 \mathrm{hr}$ after death. These postmortem changes were milder than those seen in the distal tubules, and the cytoplasmic vacuoles seen in the distal tubules at this time were not observed in the proximal tubules (Fig. 8a). Morphologically, lysosomes preserved normal structure, and cytochemically the reaction products indicating ACPase activity were, in most cases, localized in the lysosomes (Fig. 8b).

F. Effects of flushing with PBS containing ouabain, ATP, verapamil, and EDTA

The severity of the postmortem changes at room temperature observed $5 \mathrm{hr}$ after death in the rat kidneys flushed with above solutions is presented in Table 2. The postmortem changes in the proximal tubules are not presented because the changes were limited to mild karyopyknosis even without flushing.

In the kidneys flushed with the control PBS, karyopyknosis and cytoplasmic vacuolization were observed histologically in most of the epithelial cells of the distal tubules (Fig. 9a) and in about half of the epithelial cells of the TAL (Fig. 9b) $5 \mathrm{hr}$ after death. The severity of these changes was almost the same as that in the kidneys of the non-treated rats sacrificed by ether anesthesia.
In the kidneys flushed with the ouabain solution, the number of epithelial cells showing karyopyknosis and cytoplasmic vacuolization was decreased in the distal tubules (Fig. 10a), and these changes were rarely observed in the TAL (Fig. 10b). The kidneys flushed with the ATP or verapamil solution showed almost the same changes as those flushed with ouabain.

In the kidneys flushed with the PBS solution containing ouabain and verapamil (Figs. 11a, b), or ouabain and EDTA, the postmortem changes were rarely observed in both the distal tubules and TAL. In the kidneys flushed with the PBS solution containing ATP and verapamil, very slight karyopyknosis and cytoplasmic vacuolization were observed in a few epithelial cells of the distal tubules, but no appreciable postmortem changes were observed in the TAL.

Electron microscopically, marked cytoplasmic vacuolization, coagulation of the nuclear chromatin, disruption of the organellae, and marked lamination of basal infolding membranes were observed in the epithelial cells of the distal tubules in the kidneys flushed with control PBS (Fig. 12). In the kidneys flushed with the ouabain solution, the changes were much milder than those in the control group, and mild swelling of the mitochondria, mild dilatation of the endoplasmic reticulum, and sporadic lamination of the basal infolding membrane were observed in the distal tubules (Fig. 13). In the ATP group, only mild changes, the same as those in the ouabain group, were observed in the distal tubules, that is, mild swelling of the mitochondria, mild dilatation of the endoplasmic reticulum, and sporadic lamination of the basal in-

TABLE 2. Severity of postmortem changes at room temperature observed $5 \mathrm{hr}$ after death in the rat kidneys flushed with several solutions

\begin{tabular}{lcc}
\hline Flush solution & TAL $^{\mathrm{a}}$ & Distal tubule \\
\hline Vehicle & + & + \\
$10 \mathrm{mM}$ Ouabain & - & + \\
$1 \mathrm{mM}$ Verapamil & \pm & + \\
$10 \mathrm{mM}$ Ouabain $+1 \mathrm{mM}$ Verapamil & - & - \\
$10 \mathrm{mM}$ Ouabain $+10 \mathrm{mM}$ EDTA, $\left.4 \mathrm{Na}^{\mathrm{b}}\right)$ & - & - \\
$10 \mathrm{mM}$ ATP, $2 \mathrm{~K}^{\mathrm{c}}$ & - & \pm \\
$10 \mathrm{mM}$ ATP, $2 \mathrm{~K}+1 \mathrm{mM}$ Verapamil & - & \pm \\
\hline
\end{tabular}

Grades of postmortem changes were determined based on severity and frequency of karyopyknosis and cytoplasmic vacuolization of the epithelial cells examined by light microscopy and are expressed as follows: -, none; \pm , very slight; + , slight; + , moderate. Dulbecco's phosphate buffered saline [PBS] was used as the vehicle, and the kidney was flushed with $5 \mathrm{ml}$ of each solution from the abdominal aorta of rats under ether anesthesia. a) TAL: thick ascending limb of Henle's loop b) EDTA, 4Na: ethylenediaminetetraacetic acid, tetrasodium salt c) ATP, $2 \mathrm{~K}$ : adenosine triphosphate, dipotassium salt 


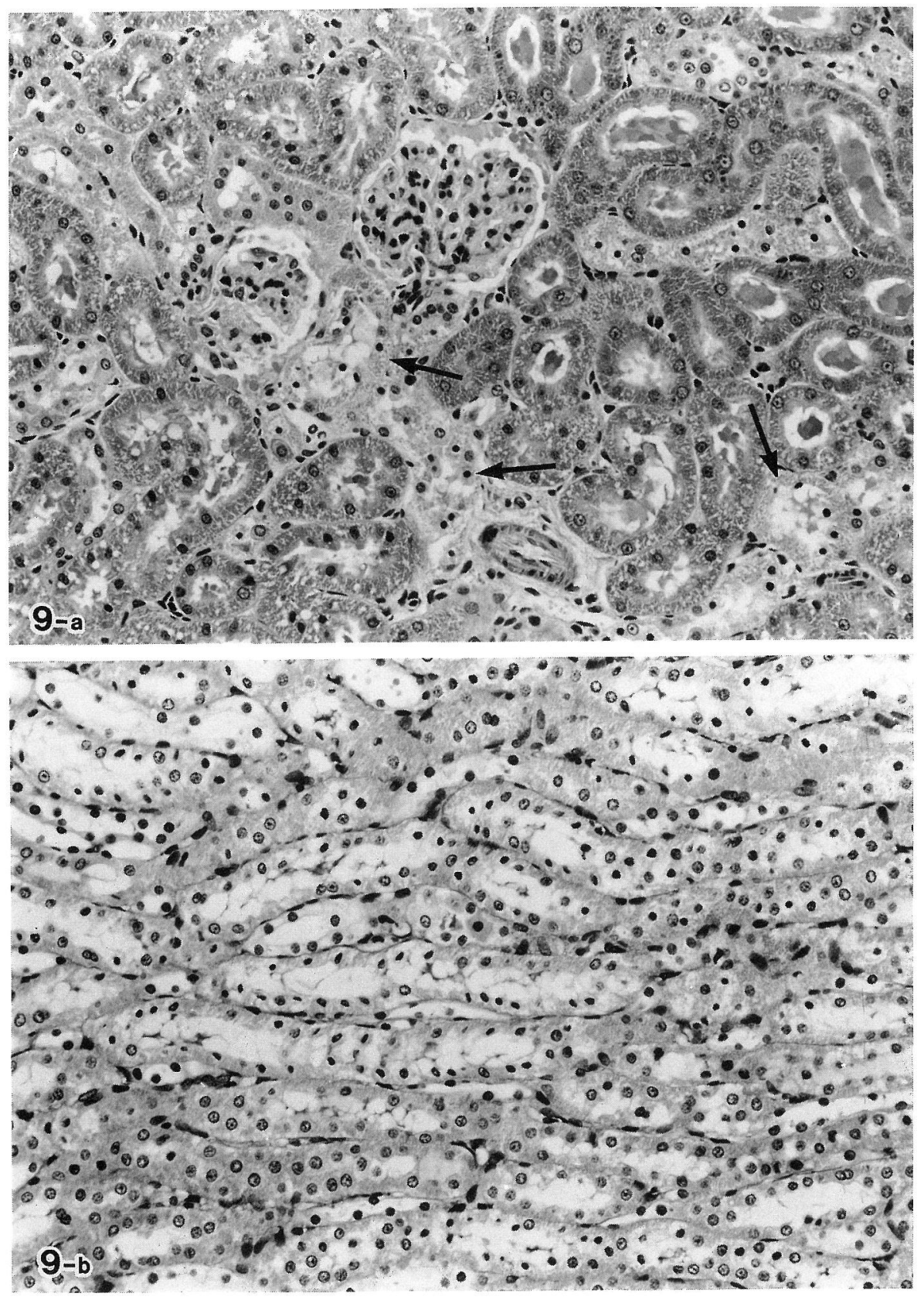

Figs. 9a, b. The rat kidney $5 \mathrm{hr}$ after death and flushing with PBS. a. Cortex. Most of the epithelial cells of the distal tubules (arrows) show vacuolization and karyopyknosis. HE stain. $\times 250$ b. Outer medulla. About the half of the epithelial cells of the thick ascending limb of the loop of Henle show marked vacuolization and karyopyknosis. HE stain. $\quad \times 250$

folding membrane (Fig. 14). In the kidneys flushed with ouabain plus verapamil, the same changes as above were observed in the distal tubules; however, the number of places in the basal infolding membrane showing lamination was less than that in the ouabain or ATP groups (Fig. 15). In the ATP plus verapamil group, the same findings as those in the ouabain plus verapamil group were observed in the distal tubules.

\section{DISCUSSION}

We have studied the postmortem changes in various organs of rats sacrificed by ether anesthesia in an effort to differentiate toxic changes from 


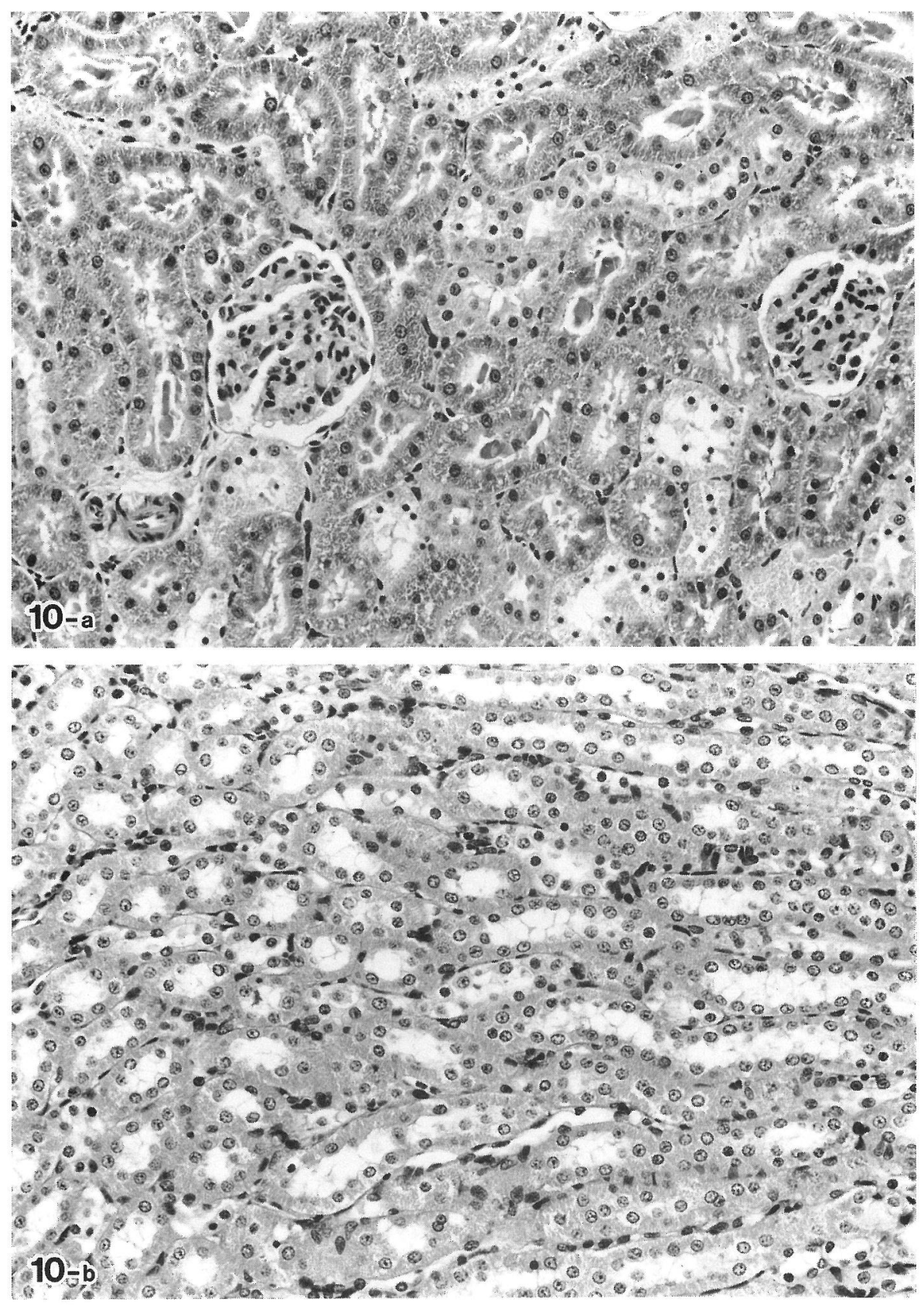

FIGS. 10a, b. The rat kidney $5 \mathrm{hr}$ after death and flushing with $10 \mathrm{mM}$ ouabain. a. Cortex. A small number of epithelial cells of the distal tubules show vacuolization and karyopyknosis. HE stain. $\times 250$ b. Outer medulla. No obvious changes are observed in the epithelial cells of thick ascending limb of the loop of Henle except for karyopyknosis in a few cells. HE stain. $\quad \times 250$

postmortem changes in animals found dead in toxicity studies of the drugs (15). In the course of the study, we noticed that the rapidity of the postmortem changes in the kidncy varies with the part of the nephron (16, 23). In this study, we found that the rapidity of the postmortem changes is related to the intensity of oua- bain-sensitive K-NPPase, a phosphatase moiety of $\mathrm{Na}, \mathrm{K}$-ATPase $(1,11,17)$. In the distal tubules and TAL, which show intense Na, K-ATPase activity (24), the postmortem changes were observed earlier and proceeded more rapidly than those in the proximal tubules, the macula densa, and other areas showing 


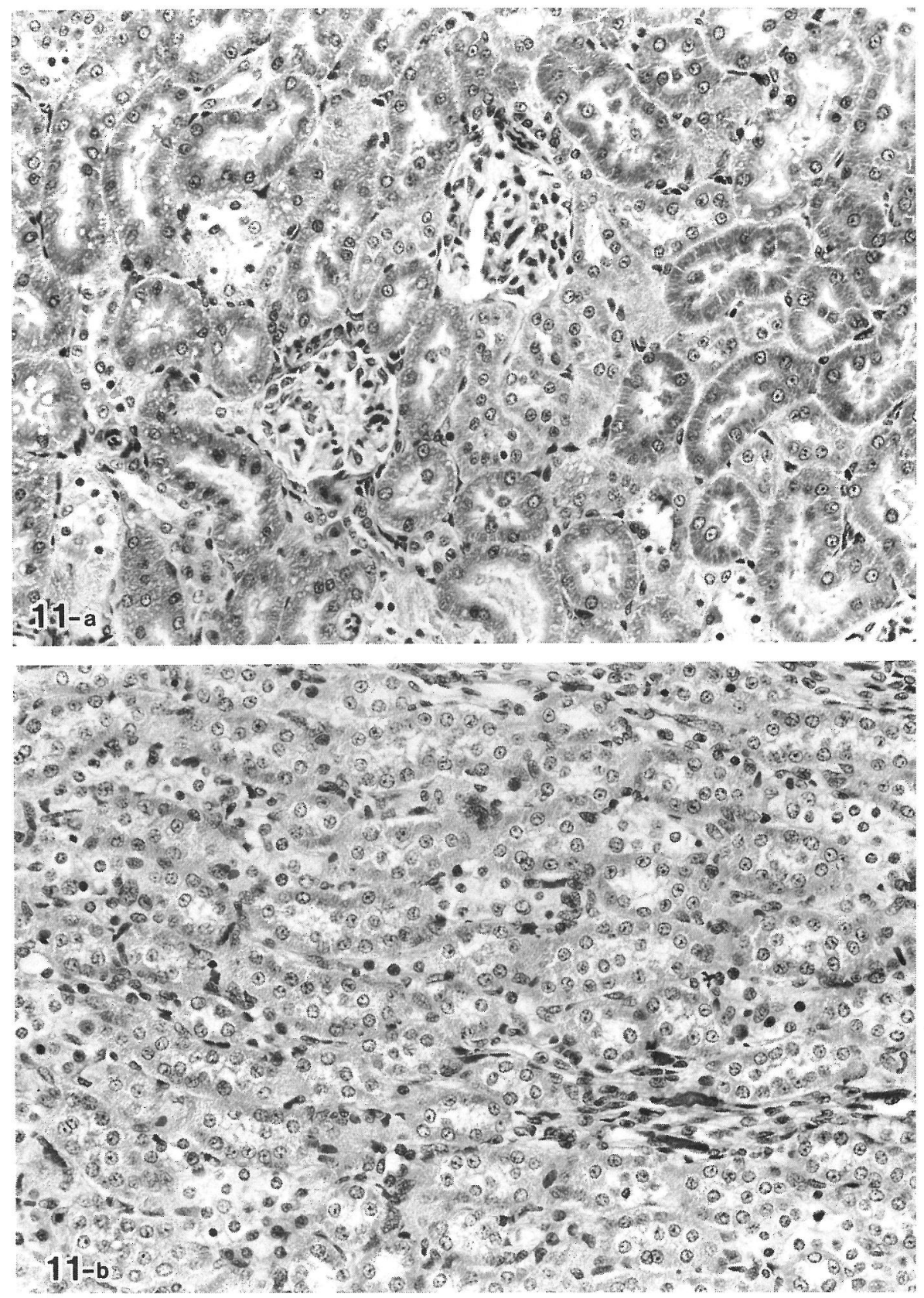

FIg. 11a, b. The rat kidney $5 \mathrm{hr}$ after death and flushing with $10 \mathrm{mM}$ ouabain and $1 \mathrm{mM}$ verapamil. a. Cortex. No obvious changes are observed in the epithelial cells of the distal tubules. HE stain. $\times 250$ b. Outer medulla. No obvious changes are observed in the epithelial cells of thick ascending limb of the loop of Henle except for karyopyknosis in a few cells. HE stain. $\times 250$

weak $\mathrm{Na}, \mathrm{K}$-ATPase activity. Na, K-ATPase acts as a sodium pump and consumes ATP as an energy source (12). Therefore, the cells with strong $\mathrm{Na}, \mathrm{K}$ ATPase activity consume much ATP. Na, K-ATPase is considered to consume ATP even after death under the appropriate conditions, because activity of this enzyme could be detected on the basal infolding membrane in the distal tubules even several hr after death as shown in the present study. However, the supply of ATP, which is produced mainly by aerobic phosphorylation in the mitochondria, is stopped by anoxia after death. Therefore, in the cells with strong 

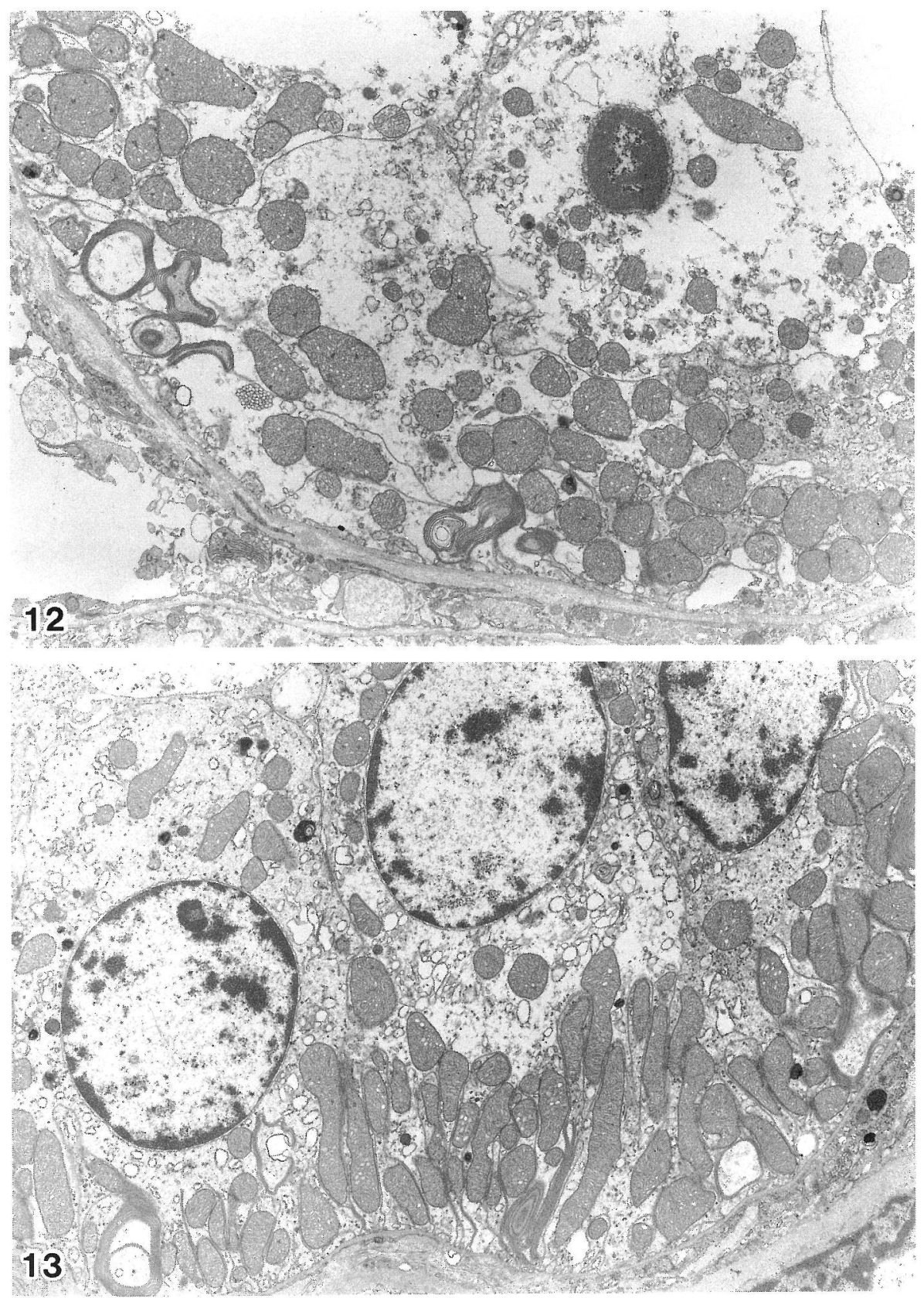

FIG. 12. Electron micrograph of distal tubule cells in the rat kidney $5 \mathrm{hr}$ after death and flushing with PBS. The epithelial cells show marked vacuolization, coagulation of the nuclear chromatin, disruption of organellae, and lamination of the basal infolding membranes. $\times 5,000$

Fig. 13. Electron micrograph of distal tubule cells in the rat kidney $5 \mathrm{hr}$ after death and flushing with $10 \mathrm{mM}$ ouabain. The epithelial cells show mild swelling of the mitochondria, mild dilatation of endoplasmic reticulum, and mild lamination of the basal infolding membranes. $\times 5,000$

$\mathrm{Na}, \mathrm{K}$-ATPase activity, the intracellular ATP concentration is assumed to decrease more rapidly after death than that in the cells with weak $\mathrm{Na}, \mathrm{K}$-ATPase activity.
On the other hand, it is known that the concentration of intracellular calcium ions must be controled to maintain the morphology of the cells: an increase in the intracellular calcium concentration causes damage 

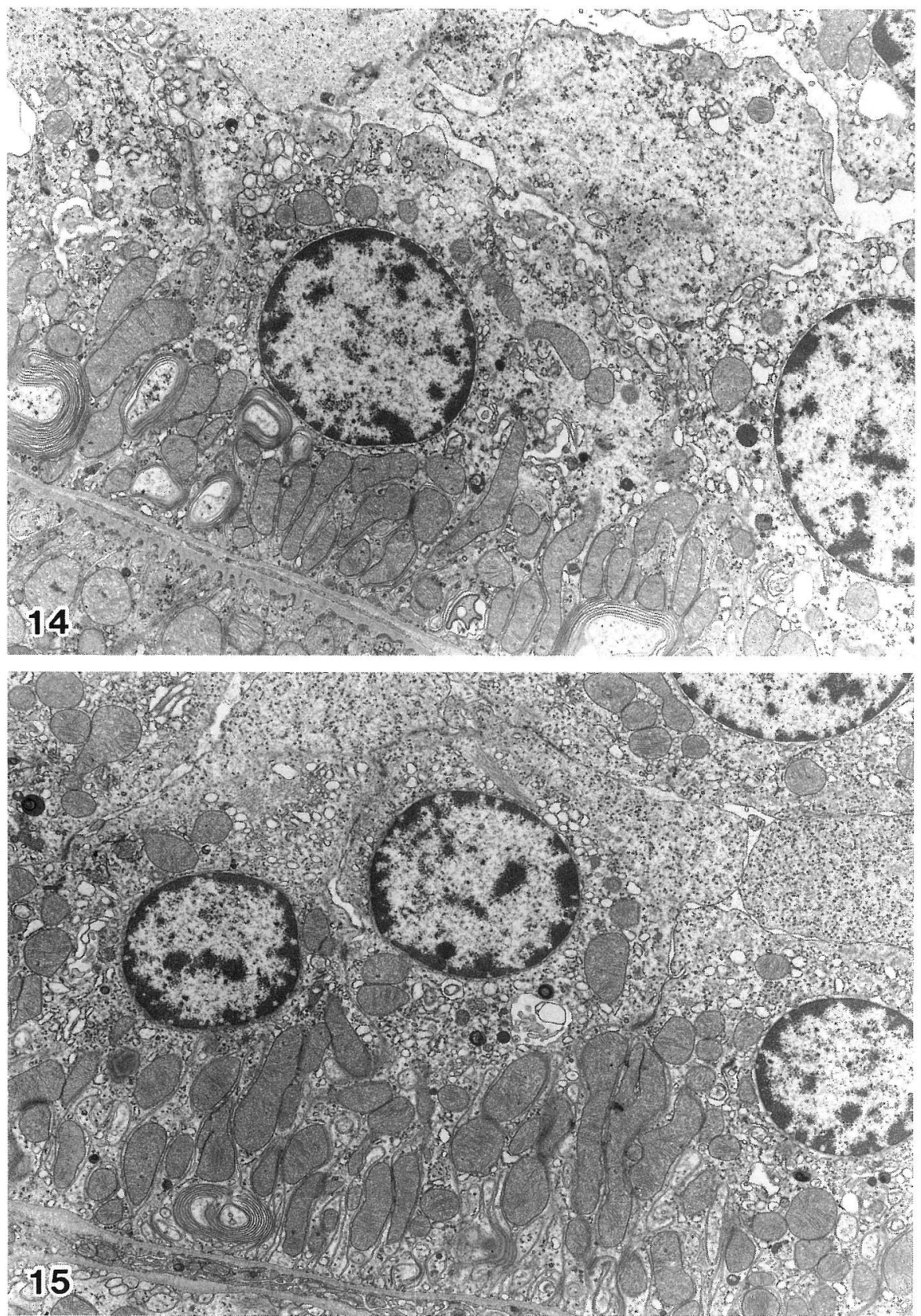

FIG. 14. Electron micrograph of distal tubule cells in the rat kidney $5 \mathrm{hr}$ after death and flushing with $10 \mathrm{mM}$ ATP. The epithelial cells show mild swelling of the mitochondria, mild dilatation of endoplasmic reticulum, and mild lamination of the basal infolding membranes. $\times 5,000$

FIG. 15. Electron micrograph of distal tubule cells in the rat kidney $5 \mathrm{hr}$ after death and flushing with $10 \mathrm{mM} \mathrm{ATP}$ and $1 \mathrm{mM}$ verapamil. The epithelial cells show mild swelling of the mitochondria, mild dilatation of endoplasmic reticulum, and mild lamination of the basal infolding membranes. However, the frequency of lamination of the basal infolding membranes is less than that in Fig. 13 or $14 . \times 5,000$

to the cytoskeleton and membranes by dissociating actin filaments from $\alpha$-actinin, by activating proteases that cleave actin-binding proteins $(25,26,29,31)$, and by activating phospholipases that catalyze hydrolysis of membrane phospholipids $(20,26)$. The intracellular calcium concentration is kept much lower than the extracellular level in normal cells by active transport consuming ATP, and when the intracellular 
ATP level decreases rapidly, the intracellular calcium concentration increases rapidly $(6,27)$, and soon causes cell damage.

We assumed that the postmortem changes would proceed more slowly when the consumption of ATP was decresed by inhibiting cellular $\mathrm{Na}, \mathrm{K}$-ATPase activity. Therefore, we studied the postmortem changes in rat kidneys flushed with a PBS solution containing ouabain, a specific inhibitor of $\mathrm{Na}, \mathrm{K}$-ATPase. In the control kidneys flushed with PBS, the epithelial cells of the distal tubules and TAL showed obvious postmortem changes, karyopyknosis and cytoplasmic vacuolization, $5 \mathrm{hr}$ after death at room temperature. However, when the kidneys were flushed with ouabain solution at the time of death, no appreciable changes were observed histopathologically in the TAL, and only mild changes were observed in the distal tubules. This indicates that the progression of the postmortem changes in the distal tubules and TAL depends on the consumption of intracellular ATP. However, the postmortem changes in the distal tubules were not completely suppressed because calcium ion influx into the cells occurred at a very low rate even when $\mathrm{Na}, \mathrm{K}$-ATPase was inhibited by ouabain $(18,19)$.

To verify the hypothesis that the rapidity of the decrease in the intracellular ATP concentration is the main factor determining the rapidity of cellular postmortem changes, ATP was supplemented by flushing the kidney at the timề of animal death. In the result, only little postmortem changes in TAL were observed, and progression of those in the distal tubules also delayed. This result indicates that influx of the exogenous ATP into the cells after death occurs and makes up for the loss of endogenous ATP consumed by $\mathrm{Na}, \mathrm{K}$-ATPase. Lytton et al. also reported that renal function after ischemia was improved by ATP$\mathrm{MgCl}_{2}$ perfusion (21).

We assumed that if we prevented calcium influx into the cells, and at the same time inhibited cellular ATP consumption, the postmortem changes would be further delayed. The concurrent use of verapamil, a calcium channel blocker (10), or EDTA, a calcium chelator, with ouabain actually delayed the postmortem changes in the TAL and the distal tubules more effectively than the use of ouabain alone. Furthermore, the concurrent use of verapamil and ATP delayed the postmortem changes more effectively than the use of ATP alone. These results indicate that both the intracellular ATP level and the intracellular calcium level are factors determining the rapidity of the posmortem changes in the distal tubules and TAL.

Lysosomes contain various kinds of proteases and amidases $(2-5,7,8,27)$, and these are thought to play a part in the digestion of foreign bodies and degeneration of organellae or cellular autolysis during tissue growth (14) and in autolysis after death (9). However, in the present study, in which we examined the postmortem changes up to $20 \mathrm{hr}$ after death at room temperature, we found that the changes in the proximal tubular cells which have a large number of lysosomes progressed slower than those in the distal tubules and TAL, areas with a small number of lysosomes. Additionally, up to $10 \mathrm{hr}$ after death, lysosomes showed no appreciable morphological changes, and hardly any leakage of ACPase was observed cytochemically. Therefore, lysosomes do not appear to play a large role in the progression of the postmortem changes in the rat kidney until at least $10 \mathrm{hr}$ after death at room temperature.

\section{REFERENCES}

1. Bader, H. and Sen, A. K.: K-dependent acylphosphatase as part of the $\mathrm{Na}^{+}, \mathrm{K}^{+}$-ATPase of cell membranes. Biochim. Biophys. Acta 118; 116-123, 1966.

2. Balasubramaniam, K. and Deiss, W. P.: Characteristics of thyroid lysosomal cathepsin. Biochim. Biophys. Acta $110 ; 564-575,1965$.

3. Bouma, J. M.W. and Gruber, M.: Intracellular distribution of cathepsin $\mathrm{B}$ and cathepsin $\mathrm{G}$ in rat liver. Biochim. Biophys. Acta 113; 350-358, 1966.

4. Bowers, W. E. and deDuve, C.: Lysosomes in lymphoid tissue. II. Intracellular distribution of acid hydrolases. J. Cell Biol. 32; 339-348, 1967.

5. Coffey, J. W. and deDuve, G.: Digestive activity of lysosomes. J. Biol. Chem. 243; 3255-3263, 1968.

6. Grompton, M., Moser, R., Lüdi, H. and Carafoli, E.: The interrelations between the transport of sodium and calcium in mitochondria of various mammalian tissues. Eur. J. Biochem. 82; 25-31, 1978.

7. DeDuve, C., Pressman, B. C., Gianetto, R., Wattiaux, R. and Applemans, F.: Tissue fractionation studies 6. Intracellular distribution patterns of enzymes in rat liver tissues. Biochem. J. 60; 604-617, 1955.

8. DeDuve, G., Wattiaux, R. and Baudhuin, P.: Distribution of enzymes between subcellular fractions in animal tissues. Advan. Enzymol. 24; 291-358, 1962.

9. DeDuve, C.: The lysosome in retrospect. In "Lysosomes in Biology and Pathology", vol. 1. 2nd ed., ed by J. T. Dingle and H. B. Fell, North-Holland Publishing Company, Amsterdam, 1973, p. 3.

10. Eisinger, D. R., Suranyi, M. G., Bracs, P., Fransworth, A. and Sheil, A. G. R.: Effects of verapamil in the prevention of warm ischaemia induced acute renal failure in dogs. Aust. N. Z. J. Surg. 55; 391-396, 1985.

11. Fujita, M., Nakao, T., Tashima, Y., Mizuno, N., Nagano, K. and Nakao, M.: Potassium ion stimulated p-nitrophenyl phosphatase activity occurring in a highly specific adenosine triphosphatase preparation from rabbit 
brain. Biochim. Biophys. Acta 117; 42-53, 1966.

12. Goldin,. S. M.: Active transport of sodium and potassium ions by the sodium and potassium ion activated adenosine triphosphatase from renal medulla: reconstitution of the purified enzyme into a well defined in vitro transport system. J. Biol. Chem. 252; 5630-5642, 1977.

13. Gomori, G.: An improved histochemical technique for acid phosphatase. Stain Technol. 25; 81-85, 1950:

14. Hurle, J. and Hinchliffe, J. R.: Cell death in the posterior necrotic zone (PNZ) of the chick wing-bud: a stereoscan and ultrastructural survey of autolysis and cell fragmentation. J. Embryol. exp. Morph. 43; 123-136, 1978.

15. Ito, T., Ando, T. and Miyajima, H.: Histopathological study on the postmortem changes in the rat. Kansai J. Lab. Anim. 2; 37, 1986 (Abstr. in Jpn.).

16. Ito, T., Morishima, H., Ando, T., Mayahara, H. and Miyajima, H.: Postmortem changes in the rat kidney. I. Histopathological, histo- and cytochemical studies-. Proc. Jpn. Soc. Histochem. Cytochem. 26; 35, 1985 (Abstr. in Jpn.).

17. Judah, J. D., Ahmed, K. and McLean, A. E. M.: Ion transport and phosphoproteins of human red cells. Biochim. Biophys. Acta. 65; 472-480, 1962.

18. Komulainen, H. and Bondy, S. C.: Increased free intrasynaptosomal $\mathrm{Ca}^{2+}$ by neurotoxic organometals: distinctive mechanisms. Toxicol. Appl. Pharmacol. 88; 7786, 1987.

19. Komulainen, H. and Bondy, S. C.: Increased free intracellular $\mathrm{Ca}^{2+}$ by toxic agents: an index of potential neurotoxicity? TiPS 9; 154-156, 1988.

20. Kunze, H., Nahas, N., Traynor, J. R. and Wurl, M.: Effects of local anaesthetics on phospholipases. Biochim. Biophys. Acta 441; 93-102, 1976.

21. Lytton, B., Vaisbort, V. R., Glazier, W. B., Chaudry, I. H. and Baue, A. E.: Improved renal function using adenosine triphosphate-magnesium chloride in preserva- tion of cannine kidneys subjected to warm ischemia. Transplantation 31; 187-189, 1981.

22. Mayahara, H., Fujimoto, K., Ando, T. and Ogawa, K.: A new one-step method for the cytochemical localization of ouabain-sensitive, potassium-dependent $p$-nitrophenylphosphatase activity. Histochemistry 67; 125-138, 1980.

23. Mayahara, H., Ito, T., Ando, T. and Miyajima, H.: Postmortem changes in the rat kidney. II. Cytochemical study on the mechanisms of the postmortem changes. Proc. Jpn. Soc. Histochem. Cytochem 26; 35, 1985 (Abstr. in Jpn.).

24. Mayahara, H. and Ogawa, K.: Ultracytochemical localization of ouabain-sensitive, potassium-dependent $p$ nitrophenylphosphatase activity in the rat kidney. Acta Histochem. Cytochem. 13; 90-102, 1980.

25. Mirabelli, F., Salis, A., Vairetti, M., Bellomo, G., Thor, H. and Orrenius, S.: Cytoskeletal alterations in human platelets exposed to oxidative stress are mediated by oxidative and $\mathrm{Ca}^{2+}$-dependent mechanisms. Arch. Biochem. Biophys. 270; 478-488, 1989.

26. Orrenius, S., McConkey, D. J., Bellomo, G. and Nicotera, P.: Role of $\mathrm{Ca}^{2+}$ in toxic cell killing. TiPS 10; 281-285, 1989.

27. Osornio, A. R., Berezesky, I. K., Mergner, W. J. and Trump, B. F.: Mitochondrial membrane fusions in experimental myocardial infarction. Fed. Proc. Fed. Am. Soc. Exp. Biol. 39; 634, 1980.

28. Shibko, S. and Tappel, A. L.: Rat-kidney lysosomes: Isolation and properties. Biochem. J. 95; 731-741, 1965.

29. Schliwa, M.: Proteins associated with cytoplasmic actin. Cell 25; 587-590, 1981.

30. Spurr, A. R.: A low-viscosity epoxy resin embedding medium for electron microscopy. J. Ultrast. Res. 26; 3143, 1969.

31. Weeds, A.: Actin-binding proteins-regulators of cell architecture and motility. Nature 296; 811-816, 1982. 